\title{
Prevention and Management of Bleeding Episodes in Children with Hemophilia
}

\author{
Rolf C. R. Ljung ${ }^{1,2}$ (1)
}

Published online: 21 August 2018

(c) The Author(s) 2018

\begin{abstract}
Regular prophylactic treatment with factor VIII (FVIII) and factor IX (FIX) concentrates in hemophilia A and B, respectively, is introduced in early infancy and has resulted in dramatic improvement of the conditions. Recombinant FVIII and FIX concentrates have been available for $>25$ years and have been modified and refined through the years; however, unfortunately frequent intravenous administrations are still necessary. The half-lives of these products have now been extended (EHL) by fusion with albumin, the Fc-portion of IgG, or by being PEGylated. This has been very successful for EHL-FIX, with 3-5 times longer half-life, and to a lesser degree for EHL-FVIII with a half-life extension of only 1.5 times the conventional products. New treatment principles using FVIII mimetics or monoclonal antibodies that rebalance the pro- and anti-coagulation system by interfering with production of anti-thrombin or tissue factor pathway inhibitor have the benefits of long-lasting activity, subcutaneous administration, and being useful in patients both with and without neutralizing antibodies. As the ultimate treatment, recent progress has also been made with gene therapy of both hemophilia A and B.
\end{abstract}

\section{Key Points}

Recombinant factor VIII (FVIII) and factor IX (FIX) intravenously administered coagulation concentrates have been available since the early $1990 \mathrm{~s}$, but plasmaderived products are still used and are in some studies thought to cause less neutralizing antibodies.

Extended half-life (EHL) recombinant FVIII and FIX products are entering the market and prolong the half-life by approximately 1.5 times (FVIII) and 3-5 times (Factor IX) conventional concentrates.

New long-acting and subcutaneously administered products have entered the market or are in the pipeline that are mimetic of FVIII or act by changing the balance of coagulation-anticoagulation in plasma and can also be used in patients with neutralizing antibodies against FVIII/FIX.

Rolf C. R. Ljung

Rolf.Ljung@med.lu.se

1 Department of Clinical Sciences-Paediatrics, Lund University, Lund, Sweden

2 Centre for Thrombosis and Haemostasis, Skåne University Hospital, Malmö, Sweden

\section{Introduction}

Hemophilia A and B are X-chromosomal recessive bleeding disorders caused by deficiency or lack of coagulation factor VIII (FVIII) or factor IX (FIX), respectively, in plasma. Depending on the concentration of FVIII or FIX, the disorders are classified as severe (FVIII/IX $<0.01 \mathrm{U} / \mathrm{mL}$ ), moderate $(0.01-0.05 \mathrm{U} / \mathrm{mL})$, or mild $(0.05-0.40 \mathrm{U} / \mathrm{mL})$. Due to the $\mathrm{X}$-chromosomal inheritance, males are almost exclusively affected while females are carriers; however, in rare cases females may also have symptoms of disease, usually due to the preferential inactivation of one of the $\mathrm{X}$ chromosomes (Lyonization phenomenon) [1]. The prevalence of hemophilia $\mathrm{A}$ is approximately 1:7500 males and of hemophilia $\mathrm{B}$ is 1:30,000 males. In the severe forms and, to a lesser degree, in the moderate forms, bleeds occur spontaneously or after trauma. The severe forms are usually diagnosed during the first year of life due to abnormal subcutaneous hematoma after minimal trauma, or hematomas may occur spontaneously. When the child begins to walk, the typical bleeds in joints and muscles begin and, before treatment was available, they resulted in crippling arthropathy early in life. The typical joints to be affected are the ankles, knees, and elbows. Life-threatening bleeds may occur and intracranial hemorrhages were previously a frequent cause of death. In the early 1960s, when treatment became available, 
the median age of death in a country with well developed health care was around 20 years, while today, with adequate treatment, life expectancy is almost as for a non-hemophilia individual [2]. The milder forms of hemophilia are often diagnosed in early childhood after excessive bleeding following trauma or surgical/dental procedures, but may remain unrecognized until later in life.

\section{The Development of Factor Replacement Therapy}

The early milestones of treatment of hemophilia with replacement of the missing coagulation factor were when the so-called Fraction I- 0 containing FVIII was isolated from plasma in the late 1950s [3], and the finding and use of cryoprecipitate as a source of FVIII in the early 1960s [4]. FIX concentrate from plasma became available soon afterwards [5], but almost 10 years later was more widely used in clinical practice [6]. These first concentrates were not pure and contained many other proteins in addition. In the early 1980s, it was found that plasma-derived concentrates could transmit viruses such as HIV and hepatitis $\mathrm{C}$ (at the time non-A, non-B hepatitis) [7, 8], which prompted the development of FVIII and FIX concentrates that were manufactured with several different virus inactivation steps such as pasteurization, solvent/detergent method, and nanofiltration as well as rigorous screening of blood donors [9, 10]. Despite several virus inactivation/elimination steps, some viruses are known to pass through, however, without any known clinical disease or problem associated with them [11]. In the 1990s, prions also became a matter of concern [12]. The AIDS disaster highly motivated and accelerated the development of recombinant FVIII and FIX, and in the late 1980s the first patients were treated with a recombinant FVIII (rFVIII) and slightly later recombinant FIX (rFIX) [13-16]. The first generation of recombinant products had human or animal proteins in the manufacturing process and human albumin had to be added in the final products. Later generations of recombinant products have been refined and contain no human constituents. Recombinant FVIII may be produced in $\mathrm{CHO}$ (Chinese hamster ovary) [17], BHK (baby hamster kidney) [18] or HEK (human embryonic kidney) [19] cell lines and may be full-length FVIII, B-domain depleted, or B-domain truncated FVIII [17, 18, 20-22]. Recombinant FIX is produced in $\mathrm{CHO}$ cells that produce the fully carboxylated mature FIX protein and without human or animal proteins being used in the manufacturing process [23], and the original product was later slightly reformulated [24].

\section{Factor Replacement and Development of Inhibitors}

The worst complication of replacement therapy for hemophilia is the development of neutralizing antibodies (inhibitors) against FVIII or FIX. Inhibitors usually develop within the first 50 exposures with a frequency varying between studies between 20 and $40 \%$ of previously untreated patients (PUPs) with severe hemophilia A and around 10\% in the milder forms, while in hemophilia B the frequency is lower, usually around $2-5 \%$ (in some studies 15-20\%) [25-27]. The majority of inhibitors generally occur within the first 20 exposure days [28] and are quantified by the Bethesda assay usually with the 'Nijmegen modification' [29]. One Bethesda unit (1 BU) is defined as the amount of inhibitor needed to inactivate $50 \%$ of the FVIII/IX present in pooled normal plasma. Depending on the peak inhibitor titer measured with the Bethesda assay, inhibitors are classified as 'low-responding'/'low-titer' $(<5 \mathrm{BU})$ or 'highresponding'/'high-titer' ( $>5 \mathrm{BU}$ ). From the clinical point of view, this is a rather useful classification since the inhibitory effect of the low-titer inhibitors can usually be overcome by increasing the dose of FVIII/FIX, and no anamnestic response in titer will occur. Some 'low-titer' inhibitors are transient and will disappear without treatment while others remain or may progress to 'high titer' [30].

Since the introduction of rFVIII, it has been a matter of debate whether the recombinant concentrates are associated with a higher frequency of inhibitors, and divergent results have been published $[31,32]$. During recent years, the large $(n=574)$ PedNet prospective observational PUP registry has shown no difference in frequency of inhibitors between plasma-derived and recombinant FVIII [33]. The cumulative incidence of all inhibitors was 32.4 and $22.4 \%$ for high-titer inhibitors. Plasma-derived products conferred a risk of inhibitor development that was similar to the risk with recombinant products (adjusted hazard ratio as compared with recombinant products, 0.96; 95\% confidence interval [CI] 0.62-1.49 [33]. The first randomized PUP trial between pdFVIII and rFVIII (SIPPET [Survey of Inhibitors in Plasma-Product Exposed Toddlers]) did, however, show that patients treated with plasma-derived FVIII (pdFVIII) containing von Willebrand factor had a lower incidence of inhibitors than those treated with rFVIII [34]. The cumulative incidence of all inhibitors in this study was $26.8 \%$ (95\% CI 18.4-35.2) with pdFVIII and 44.5\% (95\% CI 34.7-54.3) with rFVIII; the cumulative incidence of high-titer inhibitors was $18.6 \%$ (95\% CI $11.2-26.0)$ and $28.4 \%$ (95\% CI 19.6-37.2), respectively. However, several aspects of the SIPPET study have been criticized, as well as the validity of an observational study versus a randomized one. One 
problem is that these studies compare class recombinant products versus class plasma-derived products, which does not take into consideration that different immunogenicity may exist between different recombinant as well as plasma-derived products. Another problem from the clinical point of view is that it takes several years to collect a statistically valid study group and when results are finally presented, the products used in the study may not be among the current choices of concentrates. At the moment one can only conclude that diverging results and opinions exist as to whether there is a difference in immunogenicity between pdFVIII and rFVIII and, furthermore, if a difference exists between various rFVIII as well as pdFVIII products depending on the variety of cell lines, manufacturing processes etc. being used. We know that risk factors for the development of inhibitors are both treatment related, such as intensive treatment or administration as prophylaxis or on demand due to bleed during the first 50-75 exposure days [28], and genetic risk factors such as type of mutation, HLA type, haplotype of immune regulatory genes and ethnicity are the most important [35-38].

In hemophilia B there has hardly been any discussion on the impact of different concentrates on the risk of developing FIX inhibitors. The type of mutation is a well known risk factor; in particular, total gene deletions [39], but an association with treatment-related risk factors, such as type of concentrate, is extremely difficult to demonstrate due to the lower risk in hemophilia $\mathrm{B}$ patients overall to develop inhibitors but also that the disease is less frequent than hemophilia $\mathrm{A}$, which makes it even more complicated to obtain valid study groups. However, the in vivo recovery of rFIX is lower than for pdFIX, but no evidence exists that this is related to neutralizing inhibitors [23].

\section{Treatment Models for Hemophilia}

Replacement with FVIII and FIX concentrates can be given on demand to treat a bleed or may be given regularly as prophylactic treatment with the aims that the trough level (lowest concentration) should not fall below a certain level (which may vary due to the aims and resources in the healthcare system) and that the patient should be bleedfree. According to a joint statement made by the World Health Organization (WHO) and the World Federation of Hemophilia (WFH), initiating prophylactic treatment at an early age (primary prophylaxis) is considered to be the optimal form of therapy for a child with severe hemophilia [40]. However, the definition of 'prophylaxis' has not been the same in different publications through the years. A uniform classification of 'prophylactic treatment' has been suggested by the Scientific and Standardization Committee (SSC) of the International Society on Thrombosis and Haemostasis (ISTH) [41]. According to this definition, primary prophylaxis is a continuous therapy starting after the first joint bleed and before the age of 3 years. Alternatively, primary prophylaxis can be a continuous treatment started before the age of 3 years in a patient without any previous joint bleed (i.e. initiated based solely on age). Secondary and tertiary prophylaxis is started later in life and with varying degrees of arthropathy according to this definition.

Prophylactic treatment was initiated early in Sweden and the Netherlands and the beneficial outcome over decades has been shown in many retrospective studies [42, 43]. The ultimate proof of concept of prophylaxis came with the randomized US study of Manco-Johnson et al. [44], in which 60 boys $<30$ months of age were randomly assigned to prophylaxis $(n=32)$ or on-demand therapy $(n=32)$. During the same time period, the boys in the prophylactic group were given three times as much FVIII compared with those taking on-demand treatment but had a median of 1.2 hemorrhages versus 17.1 per year, respectively. The prophylactic group had a mean of 0.6 joint bleeds per year compared with 4.9 for the on-demand group.

The current regimens of prophylaxis vary depending on the aim and, due to the costs of concentrates, also on the available economic resources. If the goal is just to avoid life-threatening bleeds and crippling arthropathy, the goal can in most cases be achieved by 'low-dose prophylaxis'. Several recent studies have shown a very good result in the number of joint bleeds in patients on low-dose prophylaxis compared with on-demand treatment $[45,46]$. In an Indian study with secondary prophylaxis by Verma et al. [45], $10 \mathrm{IU} / \mathrm{kg}$ was given twice weekly for almost a year, which reduced the number of joint bleeds from $0.48( \pm 0.37) /$ month to $0.08( \pm 0.13) /$ month, and this was achieved without a significant increase in consumption of concentrates compared with the on-demand group. In a Chinese study by Tang et al. [46], 34 children had a reduction in the mean number of joint bleeds from 9.9 during a 12 -week observation period on demand to 1.2 during 12 weeks on $10 \mathrm{IU} / \mathrm{kg}$ twice weekly in hemophilia A and $20 \mathrm{IU} / \mathrm{kg}$ once weekly in hemophilia B, with no significant difference in overall consumption during the two periods.

If the aim is to prevent hemophilia arthropathy and serious bleeds and enable children/adults to live a reasonably normal life, higher doses and more frequent injections are necessary. Common regimens to reach such a goal are usually $20-40 \mathrm{U} / \mathrm{kg}$ every second day or three times per week in hemophilia A and every third day or twice weekly in hemophilia B due to the longer half-life of FIX compared with FVIII $[47,48]$. In children in particular, this may cause 
problems with venous access and many children may need a central venous line (CVAD), usually a Port-A-Cath, with concomitant risk of complications [49]. This has encouraged the development of FVIII and FIX concentrates with an extended half-life, of which some have recently entered the market and others are in the pipeline from several manufacturers.

\section{Conventional Half-Life Factor VIII (FVIII)}

The original rFVIII products were full-length molecules, octocog alfa, produced in either BHK cells (Kogenate ${ }^{\circledR}$ and later improved to Kogenate $\mathrm{FS}^{\circledR}$ ) or $\mathrm{CHO}$ cells (Recombinate ${ }^{\circledR}$, later improved to Advate ${ }^{\circledR}$ ). Slightly later a B-domain deleted factor VIII, moroctocog alfa (Refacto ${ }^{\circledR}$ and later improved to Refacto $\mathrm{AF}^{\circledR} / \mathrm{Xyntha}^{\circledR}$ ), was introduced. During the last 25 years, the rFVIII concentrates have been successively refined and improved, as mentioned above, by no addition of human or animal products in the manufacturing process, more efficient virus inactivation, and also various other minor modifications that together offer conventional rFVIII products that in several aspects are better than the originally developed rFVIII molecules. One example of such a development is with octocog alfa (Kogenate FS ${ }^{\circledR}$ ) produced in BHK cells, which has been replaced with Kovaltry ${ }^{\circledR}$, where a chaperone protein is used to improve folding, and includes new improved virus inactivation and a slightly improved half-life about 1.1 times prolonged (13 h compared with $12.2 \mathrm{~h}$; absolute times dependent on age of study group etc.). Another example of developing rFVIII is simoctocog alfa $\left(\right.$ Nuwiq $\left.^{\circledR}\right)$, which is a B-domain deleted rFVIII produced in genetically modified HEK 293F cells with no animal- or human-derived materials added during the manufacturing process or to the final product. As Nuwiq ${ }^{\circledR}$ is produced in human cells, it contains posttranslational modifications comparable to human pdFVIII and which theoretically may be of importance for the immunogenicity; however, this is still to be shown in ongoing PUP studies. Also, this product shows slightly better pharmacokinetics with a median half-life of $13.7 \mathrm{~h}$ in adults compared with first-generation products (again, absolute time depending on age of study group, type of clotting assay used, etc., making exact comparisons difficult). A third variant is lonoctocog alfa (Afstyla ${ }^{\circledR}$ ), which is a single-chain recombinant FVIII produced in CHO cells. It is a construct where the B-domain occurring in wild-type full-length FVIII has been truncated and four amino acids of the adjacent acidic a3 domain have been removed (amino acids 765-1652 of full-length FVIII). The single-chain FVIII molecule has a covalent linkage between heavy and light chains that gives an increased stability and increased von Willebrand factor (VWF) affinity and a mean half-life of $14.2 \mathrm{~h}$ (chromogenic assay). This molecule illustrates the problem that occurs with some of the modified molecules, that divergent results are obtained from FVIII clotting activity depending on the type of assay used; that is, one-stage or two-stage (such as chromogenic assay), which also complicates head-to-head comparisons between concentrates.

\section{Extended Half-Life Factor VIII (EHL-FVIII)}

There is no generally agreed definition of 'extended half-life' concentrates and there is a big difference in half-life between EHL-FVIII and EHL-FIX. In this review, the designation 'EHL' will be used for concentrates that have $>1.5$ times the half-life compared with the traditional rFVIII and which have been modified with the clear aim of increasing half-life and improving pharmacokinetic properties (Table 1). As has been discussed above, the degree of half-life prolongation is dependent on which concentrate the comparison is made with and, furthermore, is dependent on the composition of the bleeding phenotypes of the study group, the ages of the patients (since children have shorter FVIII half-lives), the individual pharmacokinetics (which may vary between individuals), the method used to measure FVIII clotting activity, and if it is the mean or median half-life that is being compared, just to mention some of the most important confounders. Two main bioengineered principles have been used to prolong half-life, fusion proteins or PEGylation.

Fusion with the Fc-portion of IgG1 is one principle that combines the effect of FVIII with the properties of IgG such as binding to neonatal $\mathrm{Fc}$ receptor (FcRn), which facilitates stability and prolongs half-life. FcRn is expressed throughout life by endothelial cells and circulating monocytes, and is part of a naturally occurring pathway that is responsible for the long circulating half-life of Fc-containing proteins such as immunoglobulins. Efmoroctocog alfa (rFVIIIFc, Elocta ${ }^{\circledR} /$ Eloctate $^{\circledR}$ ) is a B-domain deleted, licensed, FVIII produced in HEK cells based on this principle. The mean half-life extension is about 1.5 [50].

The other principle used to prolong FVIII half-life is to covalently bind polyethylene glycol (PEG) to FVIII (or FIX). This protects the coagulation factors from proteolytic degradation, leading to decreased clearance from the circulation and an extended half-life. However, the technique of PEGylation varies among the various manufacturers' products. Rurioctacog alfa pegol (Adynovate ${ }^{\circledR}$ [Bax 855]) is a licensed recombinant full-length human coagulation factor VIII, produced in $\mathrm{CHO}$ cells and derived from its parent drug substance Advate ${ }^{\circledR}$, which is non-site-specific covalently conjugated, mainly in the B-domain, with one or more molecules of polyethylene glycol (MW $20 \mathrm{kDa}$ ). The PEGylated FVIII retains all the physiological functions of the FVIII molecule with the exception of binding to 
Table 1 Extended half-life factor VIII products

\begin{tabular}{|c|c|c|c|c|}
\hline Generic name & Brand/study name & Type of EHL product & Half-life adults & Half-life $<6$ years \\
\hline Efmoroctocog alfa & Elocta/Eloctate & $\begin{array}{l}\text { B-domain deleted } \\
\text { Fusion with Fc of IgG1 }\end{array}$ & $\begin{array}{l}\text { Geometric mean } \\
19.0 \mathrm{~h}^{*}(\mathrm{CI} 17.0-21.1) \\
20.9 \mathrm{~h}^{* *}(\text { CI 1 18.2-23.9) }\end{array}$ & $\begin{array}{l}\text { Geometric mean } \\
12.3 \mathrm{~h}(\mathrm{CI} 11.0-13.7)\end{array}$ \\
\hline Rurioctacog alfa pegol & Adynovate & $\begin{array}{l}\text { Full-length } \\
\text { Random PEGylation with } 20 \mathrm{kDa}\end{array}$ & $\begin{array}{l}\text { Arithmetic mean* } \\
14.69 \mathrm{~h} \pm \text { SD } 3.79^{\#} \\
16.39 \mathrm{~h} \pm \text { SD } 5.28^{\# \#}\end{array}$ & $\begin{array}{l}\text { Arithmetic mean* } \\
11.8 \pm \text { SD } 2.43^{\#}\end{array}$ \\
\hline Damoctocog alfa pegol & Jivi/BAY 94-9027 & $\begin{array}{l}\text { B-domain deleted } \\
\text { Site-specific PEGylation with } 60 \mathrm{kDa}\end{array}$ & Approx. $19.0 \mathrm{~h}$ & - \\
\hline Turoctocog alfa pegol & N8-GP & $\begin{array}{l}\text { B-domain truncated } \\
\text { Site-specific PEGylation with } 40 \mathrm{kDa}\end{array}$ & Approx. $19.0 \mathrm{~h}$ & - \\
\hline
\end{tabular}

Pharmacokinetic data when applicable according to the manufacturer's 'Product Monograph' or published study. Figures may differ slightly compared with published papers from various clinical studies depending on the study group etc. and also the type of data presented on different products (such as arithmetic or geometric mean, etc.)

EHL extended half-life

* one-stage clotting assay, ** chromogenic (two-stage) clotting assay

\# after initial dose, ${ }^{\# \#}$ after 50 exposure days

the low-density lipoprotein receptor-related protein (LRP) clearance receptor, which is probably the explanation for the approximately 1.5 times prolonged circulation time as reduced receptor binding may slow down clearance [51, 52].

Damoctocog alfa pegol ( $\mathrm{Jivi}^{\circledR}$, BAY 94-9027) is a B-domain-deleted recombinant factor VIII produced in BHK cells with a cysteine codon introduced to allow for site-directed conjugation to a single 60-kDa PEG [53], which is not yet licensed (but with regulatory application filed). The mean half-life is approximately $19 \mathrm{~h}$ compared with approximately $13 \mathrm{~h}$ with the conventional parent drug (i.e., 1.5 times prolonged). Turoctocog alfa pegol (N8-GP) is another EHL-FVIII produced in CHO cells that is not yet licensed but with regulatory applications filed, which has a 40-kDa PEG conjugated to a B-domain truncated FVIII via site-directed glycopegylation [54].

In studies, all the EHL-FVIII products have shown expected excellent efficacy when used for prophylaxis or for treatment of bleeds. Whether the modest prolongation of the half-life of FVIII will allow less frequent dosing without breakthrough bleeds or increased risk of subclinical bleeds in certain susceptible individuals remains to be investigated and depends very much on the individual pharmacokinetics of FVIII. In children with shorter FVIII half-lives it is probably most advisable to keep the frequency of dosing that can be obtained with respect to venous access. The available results from PUP and PTP (previously treated patients) have not indicated increased risk for development of inhibitors, or a protective effect, but studies are ongoing. The PEGylated products have raised concern regarding long-term side effects due to potential accumulation of PEGs. Vacuolization of certain cell types, for example in kidney cells or macrophages, has been observed after repeated treatment with high doses in animals. The significance of these finding has been discussed since it has also been seen in conjunction with other pharmaceutical products where it has not been considered a problem [55]. Other arguments to support the safety of PEGylated products have been that they exist in non-pharmaceutical products we use and also conventional FVIII products may use polyethylene glycol as a stabilizer which, however, may not be comparable to having the product linked to a PEG. Accumulation in the choroid plexus was observed with a $40-\mathrm{kDa}$ PEG in a study conducted in macaques [55]. Toxicology studies in animals are difficult to extrapolate to humans, and one has to take into account the different sizes and modes of PEGylation used in the EHL products that may give different safety profiles, and it will thus be very difficult to provide conclusive evidence of either safety or side effects without an observational long-term study and, furthermore, in such a study it will be very difficult to choose relevant outcome measures.

\section{Extended Half-Life Factor IX (EHL-FIX)}

While the EHL-FVIII products prolong the half-life by approximately 1.5 times, EHL-FIX products using the same techniques, fusion protein or PEGylation, have been much more successful and achieve a prolongation 3-5 times that of conventional FIX products (Table 2). Albutrepenonacog alfa (Idelvion ${ }^{\circledR}$ ) (rFIXFP), which is licensed, is produced by genetic fusion of the cDNA of human albumin (with a natural half-life of approximately 20 days) to the cDNA of human coagulation factor IX 
(Thr148 allelic form), which enables the protein to be produced as a single recombinant protein. The fusion protein has a cleavable linker between the rFIX and the albumin molecules that is derived from the endogenous activation peptide; that is, albumin is cleaved off when FIX is activated. The median half-time in adults of rFIXFP is $95.3 \mathrm{~h}$ ( $\min .51 .5 \mathrm{~h}$, max. $135.7 \mathrm{~h}$ ) to be compared with a mean half-life of $18.1 \mathrm{~h} \pm 5.1$ for conventional nonacog alfa (Benefix ${ }^{\circledR}$ ); that is, $4-5$ times prolongation of half-life depending on the conditions in the comparison used [56]. Eftrenonacog alfa, a FIX recombinant $\mathrm{Fc}$ fusion protein $\left(\right.$ Alprolix $\left.{ }^{\circledR}\right)(\mathrm{rFIXFc})$, a licensed product, is developed by fusing FIX to the Fc portion of IgG1. The half-life achieved is $82.12 \mathrm{~h}$ (95\% CI 71.4-94.5), which is slightly lower than the albumin fusion product (2.5-4.5 times prolongation depending on the conditions in the comparison used) [57]. Nonacog beta pegol, Refixia ${ }^{\circledR}$ (rFIXGP) is a recombinant human FIX (rFIX, Ala148 allelic form) with a 40-kDa PEG selectively attached to specific N-linked glycans in the rFIX activation peptide. Upon activation the activation peptide including the $40-\mathrm{kDa}$ polyethyleneglycol moiety is cleaved off, leaving the native activated factor IX molecule. The geometric mean half-life is $115 \mathrm{~h}$ (Coefficient of variation [CV]; 10\%) in adults and in the range $70-89 \mathrm{~h}$ in the pediatric population, which seems slightly higher than for the fusion products [58].

EHL-rFIX products enable less frequent dosing in prophylaxis in hemophilia B patients due to the considerable prolongation of half-life offered by the new products. In adult studies, a dose of $50 \mathrm{U} / \mathrm{kg}$ has shown almost $20 \%$ recovery after 1 week with the rFIXFP and rFIXPG products and approximately $10 \%$ with the rFIXFc product, and in many adults an acceptable trough can even be achieved $>2$ weeks after a dose of $80 \mathrm{IU} / \mathrm{kg}$. When prophylaxis with EHL-FIX products is started at the age of 1-2 years in children, a central venous line may be avoided in children who would otherwise require it with the frequent dosing of a conventional concentrate. The EHL-FIXs have shown the expected efficacy both in prophylaxis and in treatment of bleeds and there has not been any reports suggesting either increased or decreased risk of inhibitors. As is the case in hemophilia A, we need to gain experience on the outcome of breakthrough bleeds and subclinical bleeds with the new EHL concentrates with longer decay curves and fewer peaks, not least in physically active persons. Particularly for children with generally shorter FIX half-lives, it is advisable to keep to weekly dosing in hemophilia B. Despite these cautionary notes, the EHL-FIXs offer a 'paradigm shift' in hemophilia treatment in a much different way than the corresponding EHL-FVIII. It is probably the coupling between FVIII and VWF in blood that makes it difficult to prolong the action of FVIII.

\section{New Principles to Treat Hemophilia ('Non-Factor Treatments')}

Three new main principles have been presented, licensed, or are in the pipeline to treat hemophilia based on either a FVIII mimetic function [59] or re-balancing coagulation and anti-coagulation by interfering with the anticoagulants antithrombin (AT) or tissue factor pathway inhibitor (TFPI) [60-62]. The primary focus of these treatment options has been hemophilia complicated with an inhibitor and they offer several advantages over the conventional 'bypassing agents', such as considerably longer activity-days/weeks instead of hours - and subcutaneous administration. As a second step, some of them have also been used with success in non-inhibitor hemophilia patients, although their use in this context needs further study and experience.

Emicizumab (ACE 910) $\left(\right.$ Hemlibra $\left.^{\circledR}\right)$, is a licensed bispecific monoclonal antibody that mimics the function of the activated FVIII (FVIIIa) molecule and brings together the factor IXa and factor $\mathrm{X}$ proteins that are required to activate the natural coagulation cascade [59] (i.e., it only works in hemophilia A and not in hemophilia B). It is administered subcutaneously and has a half-life of 4-5 weeks. In a study

Table 2 Extended half-life factor IX products

\begin{tabular}{|c|c|c|c|c|}
\hline Generic name & Brand name & Type of EHL product & Half-life adults & Half-life $<6$ years \\
\hline Albutrepenonacog alfa & Idelvion & Fusion with human albumin & $\begin{array}{l}\text { Arithmetic mean } 104.2 \mathrm{~h}(\mathrm{CV} \\
25.4 \%)\end{array}$ & $\begin{array}{l}\text { Arithmetic mean } 91.0 \mathrm{~h} \\
\quad(1-12 \text { year })(\mathrm{CV} 17.7 \%)\end{array}$ \\
\hline Eftrenonacog alfa & Alprolix & Fusion with $\mathrm{Fc}$ of IgG1 & $\begin{array}{l}\text { Geometric mean } 82.1 \text { h }(95 \% \text { CI } \\
\text { 71.4-94.5) }\end{array}$ & $\begin{array}{l}\text { Geometric mean } 66.49 \text { h }(95 \% \text { CI } \\
55.8-79.1)\end{array}$ \\
\hline Nonacog beta pegol & Refixia & PEGylation with 40-kD PEG & Geometric mean 115 h (CV 10\%) & Geometric mean 70 h (CV 16\%) \\
\hline
\end{tabular}

Pharmacokinetic data according to the manufacturer's 'Product Monograph'. Figures may differ slightly compared with published papers from various clinical studies on the respective product depending on the study group etc. and also the type of data presented on different products (such as arithmetic or geometric mean, etc.)

$C V$ Coefficient of variation, $E H L$ extended half-life 
of 109 subjects with hemophilia A with inhibitors, the annualized bleeding rate was 2.9 events (95\% CI 1.7-5.0) among those who were randomly assigned to emicizumab prophylaxis compared with 23.3 events (95\% CI 12.3-43.9) among those assigned to no prophylaxis (i.e., with bypassing agents) $(p<0.001)$. In the HAVEN 3 trial program, emicizumab was administered to patients with hemophilia without inhibitors at a dosage of $1.5 \mathrm{mg} / \mathrm{kg}$ once a week or $3.0 \mathrm{mg} / \mathrm{kg}$ every second week, resulting in a 96 or $97 \%$ reduction of bleeds, respectively, compared with on-demand treatment (report at World Federation of Hemophilia Congress, May 2018). However, in the trials four serious adverse events occurred, two with venous thrombosis and two with thrombotic microangiopathy, in subjects who received concomitant activated prothrombin complex concentrates (aPCC) at high doses due to breakthrough bleeds [63]. For patients with hemophilia A and inhibitors, emicizumab offers a paradigm shift with effective, long-acting prophylaxis after subcutaneous administration once per week or every second week, compared with the short-acting bypassing agents (aPCC and rFVIIa) that require intravenous administration. The role of emicizumab in the treatment of patients without inhibitors also seems effective and attractive, but needs further evaluation concerning serious side effects such as microangiopathy, the long-term safety in various clinical situations, how to treat breakthrough bleeds, the difference in pharmacokinetics between individuals, and how to measure the prophylactic effect in comparison with conventional concentrates and thus which measurers to use to individualize treatment (dosage and dose frequency).

The other two novel non-factor treatments re-balance the pro- and anticoagulation balance in plasma. Human recombinant antibodies against TFPI are being developed by several pharmaceutical companies [60, 64]. Concizumab, a humanized monoclonal antibody against TFPI, is being developed as a subcutaneously administered treatment preventing the binding of FXa to TFPI, which results in amplified generation of FXa and thrombin in vitro [62]. A phase II efficacy and safety study is ongoing on prophylactic administration of concizumab in hemophilia A and B patients with inhibitors (ClinicalTrials.gov Identifier: NCT03196284). Other similar products are also in early developmental phases. Fitusiran, also known as ALN-AT3SC, is an RNAi therapeutic agent that targets the production of antithrombin, thus changing the balance towards coagulation by increased production of thrombin [65]. In a dose-finding study, fitusiran was administered either once weekly or once monthly. The monthly regimen induced a dose-dependent mean maximum antithrombin reduction of 70-89\% from baseline. Oncemonthly subcutaneous administration of fitusiran resulted in dose-dependent lowering of the antithrombin level and increased thrombin generation in participants with hemophilia A or B who did not have inhibitors [65].

Two phase III studies are ongoing for fitusiran in hemophilia A and B patients with and without inhibitors (ClinicalTrials.gov Identifier: NCT03417102 and ClinicalTrials. gov Identifier: NCT03417245). Concerns have been raised on the risk induced by re-balancing the delicate balance of the pro-coagulant and anti-coagulant systems, especially in situations such as serious infections that may create a pro-coagulant state, and also on how to best counteract the induced inhibition of the anti-coagulant system if necessary to avoid thrombosis.

\section{Gene Therapy}

The ultimate treatment of hemophilia is gene therapy, and recently promising results have been published on gene therapy in both hemophilia A and B [66, 67].

In hemophilia $A$, an adeno-associated virus vector (AAV) encoding a B-domain-deleted human factor VIII was injected in nine men with severe hemophilia A. It resulted in a sustained normalization of FVIII activity level to a normal value $(>50 \%)$ over a period of 1 year in six participants, some of whom also had supernormal levels on a few occasions. Bleeds decreased from 16 events before the study to one event after gene transfer and participants used much less FVIII concentrate [67].

In hemophilia B, a single-stranded AAV consisting of a bioengineered capsid, liver-specific promoter, and FIX Padua was injected and resulted in a sustained production of FIX in all the participants, with a mean $( \pm$ SD) steadystate FIX coagulant activity of $33.7 \% \pm 18.5 \%$. On follow-up in individual participants, after 28-78 weeks, the annualized bleeding rate was significantly reduced (mean rate 11.1 events per year [range 0-48] before vector administration vs 0.4 events per year [range $0-4$ ] after administration; $p=0.02$ ), as was factor use (mean dose $2908 \mathrm{IU} / \mathrm{kg}$ before vector administration vs $49.3 \mathrm{IU} / \mathrm{kg}$ after administration; $p=0.004$ ). Eight out of ten participants did not use factor, and nine of ten did not have bleeds after vector administration [66].

The recent results from gene therapy trials in hemophilia are encouraging, although many questions remain to be answered, such as how long will the effect remain and is it possible to administer the same vector again without an immune response, risk of insertional mutagenesis, risk of uncontrolled overproduction, etc. 


\section{Concluding remarks}

Hemophilia treatment is currently in a progressive phase with several modified and improved conventional recombinant FVIII/FIX concentrates, whereas we have decades of accumulated experience of the precursors, the introduction of EHL concentrates, of which the EHL-FIXs are the most interesting, and new 'non-factor' treatment principles. Finally, there is the future vision of gene therapy as the ultimate treatment, which now seems to be realizable within a reasonable timeframe.

\section{Compliance with Ethical Standards}

Funding This study was funded by a grant from the Swedish Research Council (2015-02957).

Conflict of interest The author owns no stock and is not employed in any pharmaceutical industry. The author has during the last 5 years received speaker's or educational fees from Bayer, Baxter/Shire, NovoNordisk, and Pfizer, and consultancy fees for advisory boards or data safety monitoring boards from CSL Behring, Octapharma, Baxter/ Shire, and SOBI/Bioverativ-however, with no relationship to this review.

Open Access This article is distributed under the terms of the Creative Commons Attribution-NonCommercial 4.0 International License (http://creativecommons.org/licenses/by-nc/4.0/), which permits any noncommercial use, distribution, and reproduction in any medium, provided you give appropriate credit to the original author(s) and the source, provide a link to the Creative Commons license, and indicate if changes were made.

\section{References}

1. Mannucci PM, Coppola R, Lombardi R, Papa M, de Biasi R. Direct proof of extreme lyonization as a cause of low factor VIII levels in females. Thromb Haemost. 1978;39(2):544-5.

2. Larsson SA, Nilsson IM, Blomback M. Current status of Swedish hemophiliacs. I. A demographic survey. Acta Med Scand. 1982;212(4):195-200.

3. Blomback M, Nilsson IM. Treatment of hemophilia A with human antihemophilic globulin. Acta Med Scand. 1958;161(4):301-21.

4. Pool JG, Gershgold EJ, Pappenhagen AR. High-Potency Antihaemophilic Factor Concentrate Prepared from Cryoglobulin Precipitate. Nature. 1964;203:312.

5. Prou-Wartelle O, Soulier JP. Fractions of human plasma rich in factor IX (anthemophilic factor B). Pathol Biol (Paris). 1959;7:2499-505.

6. Nilsson IM, Ahlberg A, Bjorlin G. Clinical experience with a Swedish factor IX concentrate. Acta Med Scand. 1971;190(4):257-66.

7. Daly HM, Scott GL. Fatal AIDS in a haemophiliac in the UK. Lancet. 1983;2(8360):1190.

8. Desforges JF. AIDS and preventive treatment in hemophilia. N Engl J Med. 1983;308(2):94-5.

9. Ng PK, Dobkin MB. Pasteurization of antihemophilic factor and model virus inactivation studies. Thromb Res. 1985;39(4):439-47.
10. Prowse C. Kill and cure. The hope and reality of virus inactivation. Vox Sang. 1994;67(Suppl 3):191-6.

11. Santagostino E, Mannucci PM, Gringeri A, Azzi A, Morfini M, Musso R, et al. Transmission of parvovirus B19 by coagulation factor concentrates exposed to 100 degrees $\mathrm{C}$ heat after lyophilization. Transfusion. 1997;37(5):517-22.

12. Evatt BL. Prions and haemophilia: assessment of risk. Haemophilia. 1998;4(4):628-33.

13. White GC 2nd, McMillan CW, Kingdon HS, Shoemaker $\mathrm{CB}$. Use of recombinant antihemophilic factor in the treatment of two patients with classic hemophilia. N Engl J Med. 1989;320(3):166-70.

14. Wood WI, Capon DJ, Simonsen CC, Eaton DL, Gitschier J, Keyt B, et al. Expression of active human factor VIII from recombinant DNA clones. Nature. 1984;312(5992):330-7.

15. Kaufman RJ, Wasley LC, Furie BC, Furie B, Shoemaker CB. Expression, purification, and characterization of recombinant gamma-carboxylated factor IX synthesized in Chinese hamster ovary cells. J Biol Chem. 1986;261(21):9622-8.

16. Anson DS, Austen DE, Brownlee GG. Expression of active human clotting factor IX from recombinant DNA clones in mammalian cells. Nature. 1985;315(6021):683-5.

17. Gomperts E, Lundblad R, Adamson R. The manufacturing process of recombinant factor VIII, recombinate. Transfus Med Rev. 1992;6(4):247-51.

18. Boedeker BG. The manufacturing of the recombinant factor VIII. Kogenate. Transfus Med Rev. 1992;6(4):256-60.

19. Casademunt E, Martinelle K, Jernberg M, Winge S, Tiemeyer M, Biesert $\mathrm{L}$, et al. The first recombinant human coagulation factor VIII of human origin: human cell line and manufacturing characteristics. Eur J Haematol. 2012;89(2):165-76. https://doi.org/10. 1111/j.1600-0609.2012.01804.x.

20. Lind P, Larsson K, Spira J, Sydow-Backman M, Almstedt A, Gray $\mathrm{E}$, et al. Novel forms of B-domain-deleted recombinant factor VIII molecules. Construction and biochemical characterization. Eur J Biochem. 1995;232(1):19-27.

21. Haddley K. Turoctocog alfa for the treatment of hemophilia A. Drugs Today (Barc). 2014;50(2):121-31. https://doi.org/10.1358/ dot.2014.50.2.2116671.

22. Eaton DL, Wood WI, Eaton D, Hass PE, Hollingshead P, Wion $\mathrm{K}$, et al. Construction and characterization of an active factor VIII variant lacking the central one-third of the molecule. Biochemistry. 1986;25(26):8343-7.

23. White GC 2nd, Beebe A, Nielsen B. Recombinant factor IX. Thromb Haemost. 1997;78(1):261-5.

24. Lambert T, Recht M, Valentino LA, Powell JS, Udata C, Sullivan ST, et al. Reformulated BeneFix: efficacy and safety in previously treated patients with moderately severe to severe haemophilia B. Haemophilia. 2007;13(3):233-43. https://doi.org/10.11 11/j.1365-2516.2007.01458.x.

25. Gouw SC, van der Bom JG, Auerswald G, Ettinghausen CE, Tedgard U, van den Berg HM. Recombinant versus plasma-derived factor VIII products and the development of inhibitors in previously untreated patients with severe hemophilia A: the CANAL cohort study. Blood. 2007;109(11):4693-7.

26. Osooli M, Berntorp E. Inhibitors in haemophilia: what have we learned from registries? A systematic review. J Intern Med. 2015;277(1):1-15. https://doi.org/10.1111/joim.12301.

27. Martensson A, Letelier A, Hallden C, Ljung R. Mutation analysis of Swedish haemophilia B families-high frequency of unique mutations. Haemophilia. 2016;22(3):440-5. https://doi. org/10.1111/hae.12854.

28. Gouw SC, van den Berg HM, Fischer K, Auerswald G, Carcao M, Chalmers E, et al. Intensity of factor VIII treatment and inhibitor development in children with severe hemophilia A: the RODIN 
study. Blood. 2013;121(20):4046-55. https://doi.org/10.1182/ blood-2012-09-457036.

29. Verbruggen B, Novakova I, Wessels H, Boezeman J, van den Berg M, Mauser-Bunschoten E. The Nijmegen modification of the Bethesda assay for factor VIII: C inhibitors: improved specificity and reliability. Thromb Haemost. 1995;73(2):247-51.

30. Mancuso ME, Fischer K, Santagostino E, Oldenburg J, Platokouki $\mathrm{H}$, Konigs $\mathrm{C}$, et al. Risk factors for the progression from low to high titres in 260 children with severe haemophilia a and newly developed inhibitors. Thromb Haemost. 2017;117(12):2274-82. https://doi.org/10.1160/TH17-01-0059.

31. Wight J, Paisley S. The epidemiology of inhibitors in haemophilia A: a systematic review. Haemophilia. 2003;9(4):418-35.

32. Iorio A, Halimeh S, Holzhauer S, Goldenberg N, Marchesini E, Marcucci M, et al. Rate of inhibitor development in previously untreated hemophilia A patients treated with plasma-derived or recombinant factor VIII concentrates: a systematic review. J Thromb Haemost. 2010;8(6):1256-65. https://doi.org/10.111 1/j.1538-7836.2010.03823.x.

33. Gouw SC, van der Bom JG, Ljung R, Escuriola C, Cid AR, Claeyssens-Donadel S, et al. Factor VIII products and inhibitor development in severe hemophilia A. N Engl J Med. 2013;368(3):231-9. https://doi.org/10.1056/NEJMoa1208024.

34. Peyvandi F, Mannucci PM, Garagiola I, El-Beshlawy A, Elalfy M, Ramanan V, et al. A randomized trial of factor viii and neutralizing antibodies in hemophilia A. N Engl J Med. 2016;374(21):205464. https://doi.org/10.1056/NEJMoa1516437.

35. Rosendaal FR, Palla R, Garagiola I, Mannucci PM, Peyvandi F. Genetic risk stratification to reduce inhibitor development in the early treatment of hemophilia A: a SIPPET analysis. Blood. 2017. https://doi.org/10.1182/blood-2017-06-791756.

36. Oldenburg J, Pavlova A. Genetic risk factors for inhibitors to factors VIII and IX. Haemophilia. 2006;12(Suppl 6):15-22.

37. Schwaab R, Brackmann HH, Meyer C, Seehafer J, Kirchgesser M, Haack A, et al. Haemophilia A: mutation type determines risk of inhibitor formation. Thromb Haemost. 1995;74(6):1402-6.

38. Hay CR, Ollier W, Pepper L, Cumming A, Keeney S, Goodeve AC, et al. HLA class II profile: a weak determinant of factor VIII inhibitor development in severe haemophilia A. UKHCDO Inhibitor Working Party. Thromb Haemost. 1997;77(2):234-7.

39. Giannelli F, Choo KH, Rees DJ, Boyd Y, Rizza CR, Brownlee GG. Gene deletions in patients with haemophilia B and anti-factor IX antibodies. Nature. 1983;303(5913):181-2.

40. Berntorp E, Boulyjenkov V, Brettler D, Chandy M, Jones P, Lee C, et al. Modern treatment of haemophilia. Bull World Health Organ. 1995;73(5):691-701.

41. Blanchette VS, Key NS, Ljung LR, Manco-Johnson MJ, van den Berg HM, Srivastava A, et al. Definitions in hemophilia: communication from the SSC of the ISTH. J Thromb Haemost. 2014;12(11):1935-9. https://doi.org/10.1111/jth.12672.

42. Nilsson IM, Berntorp E, Lofqvist T, Pettersson H. Twenty-five years' experience of prophylactic treatment in severe haemophilia A and B. J Intern Med. 1992;232(1):25-32.

43. van den Berg HM, Fischer K, Mauser-Bunschoten EP, Beek FJ, Roosendaal G, van der Bom JG, et al. Long-term outcome of individualized prophylactic treatment of children with severe haemophilia. Br J Haematol. 2001;112(3):561-5.

44. Manco-Johnson MJ, Abshire TC, Shapiro AD, Riske B, Hacker MR, Kilcoyne R, et al. Prophylaxis versus episodic treatment to prevent joint disease in boys with severe hemophilia. N Engl J Med. 2007;357(6):535-44.

45. Verma SP, Dutta TK, Mahadevan S, Nalini P, Basu D, Biswal N, et al. A randomized study of very low-dose factor VIII prophylaxis in severe haemophilia— a success story from a resource limited country. Haemophilia. 2016;22(3):342-8. https://doi.org/10.1111/ hae. 12838 .

46. Tang L, Wu R, Sun J, Zhang X, Feng X, Zhang X, et al. Shortterm low-dose secondary prophylaxis for severe/moderate haemophilia A children is beneficial to reduce bleed and improve daily activity, but there are obstacle in its execution: a multi-centre pilot study in China. Haemophilia. 2013;19(1):27-34. https://doi.org/1 0.1111/j.1365-2516.2012.02926.x.

47. Ljung R, Gretenkort Andersson N. The current status of prophylactic replacement therapy in children and adults with haemophilia. Br J Haematol. 2015;169(6):777-86. https://doi. org/10.1111/bjh.13365.

48. Fischer K, Ljung R. Primary prophylaxis in haemophilia care: guideline update 2016. Blood Cells Mol Dis. 2017. https://doi. org/10.1016/j.bcmd.2017.03.009.

49. Ljung R. Central venous catheters in children with haemophilia. Blood Rev. 2004;18(2):93-100.

50. Mahlangu J, Powell JS, Ragni MV, Chowdary P, Josephson NC, Pabinger I, et al. Phase 3 study of recombinant factor VIII Fc fusion protein in severe hemophilia A. Blood. 2014;123(3):31725. https://doi.org/10.1182/blood-2013-10-529974.

51. Konkle BA, Stasyshyn O, Chowdary P, Bevan DH, Mant T, Shima M, et al. Pegylated, full-length, recombinant factor VIII for prophylactic and on-demand treatment of severe hemophilia A. Blood. 2015;126(9):1078-85. https://doi.org/10.1182/blood -2015-03-630897.

52. Turecek PL, Bossard MJ, Graninger M, Gritsch H, Hollriegl W, Kaliwoda M, et al. BAX 855, a PEGylated rFVIII product with prolonged half-life. Development, functional and structural characterisation. Hamostaseologie. 2012;32(Suppl 1):S29-38.

53. Coyle TE, Reding MT, Lin JC, Michaels LA, Shah A, Powell J. Phase I study of BAY 94-9027, a PEGylated B-domain-deleted recombinant factor VIII with an extended half-life, in subjects with hemophilia A. J Thromb Haemost. 2014;12(4):488-96.

54. Giangrande P, Andreeva T, Chowdary P, Ehrenforth S, Hanabusa $\mathrm{H}$, Leebeek FW, et al. Clinical evaluation of glycoPEGylated recombinant FVIII: efficacy and safety in severe haemophilia A. Thromb Haemost. 2017;117(2):252-61. https://doi.org/10.1160/ TH16-06-0444.

55. Stidl R, Fuchs S, Bossard M, Siekmann J, Turecek PL, Putz M. Safety of PEGylated recombinant human full-length coagulation factor VIII (BAX 855) in the overall context of PEG and PEG conjugates. Haemophilia. 2016;22(1):54-64. https://doi.org/10.1111/ hae. 12762

56. Martinowitz U, Lubetsky A. Phase I/II, open-label, multicenter, safety, efficacy and PK study of a recombinant coagulation factor IX albumin fusion protein (rIX-FP) in subjects with hemophilia B. Thromb Res. 2013;131(Suppl 2):S11-4. https://doi.org/10.1016/ S0049-3848(13)70152-X.

57. Powell JS, Pasi KJ, Ragni MV, Ozelo MC, Valentino LA, Mahlangu JN, et al. Phase 3 study of recombinant factor IX Fc fusion protein in hemophilia B. N Engl J Med. 2013;369(24):2313-23. https://doi.org/10.1056/NEJMoa1305074.

58. Negrier C, Young G, Abdul Karim F, Collins PW, Hanabusa H, Colberg T, et al. Recombinant long-acting glycoPEGylated factor IX (nonacog beta pegol) in haemophilia B: assessment of target joints in multinational phase 3 clinical trials. Haemophilia. 2016;22(4):507-13. https://doi.org/10.1111/hae.12902.

59. Shima M, Hanabusa H, Taki M, Matsushita T, Sato T, Fukutake $\mathrm{K}$, et al. Factor VIII-mimetic function of humanized bispecific antibody in hemophilia A. N Engl J Med. 2016;374(21):2044-53. https://doi.org/10.1056/NEJMoa1511769.

60. Gorczyca ME, Nair SC, Jilma B, Priya S, Male C, Reitter S, et al. Inhibition of tissue factor pathway inhibitor by the aptamer BAX499 improves clotting of hemophilic blood and plasma. J 
Thromb Haemost. 2012;10(8):1581-90. https://doi.org/10.111 1/j.1538-7836.2012.04790.x.

61. Peterson JA, Maroney SA, Mast AE. Targeting TFPI for hemophilia treatment. Thromb Res. 2016;141(Suppl 2):S28-30. https ://doi.org/10.1016/S0049-3848(16)30359-0.

62. Waters EK, Sigh J, Friedrich U, Hilden I, Sorensen BB. Concizumab, an anti-tissue factor pathway inhibitor antibody, induces increased thrombin generation in plasma from haemophilia patients and healthy subjects measured by the thrombin generation assay. Haemophilia. 2017. https://doi.org/10.1111/hae.13260.

63. Oldenburg J, Mahlangu JN, Kim B, Schmitt C, Callaghan MU, Young G, et al. Emicizumab prophylaxis in hemophilia A with inhibitors. N Engl J Med. 2017. https://doi.org/10.1056/NEJMo a1703068.

64. Chowdary P, Lethagen S, Friedrich U, Brand B, Hay C, Abdul Karim F, et al. Safety and pharmacokinetics of anti-TFPI antibody (concizumab) in healthy volunteers and patients with hemophilia: a randomized first human dose trial. J Thromb Haemost. 2015;13(5):743-54. https://doi.org/10.1111/jth.12864.

65. Pasi KJ, Rangarajan S, Georgiev P, Mant T, Creagh MD, Lissitchkov T, et al. Targeting of antithrombin in hemophilia A or B with RNAi therapy. N Engl J Med. 2017. https://doi.org/10.1056/ NEJMoa1616569.

66. George LA, Sullivan SK, Giermasz A, Rasko JEJ, Samelson-Jones BJ, Ducore J, et al. Hemophilia B gene therapy with a high-specific-activity factor IX variant. N Engl J Med. 2017;377(23):221527. https://doi.org/10.1056/NEJMoa1708538.

67. Rangarajan S, Walsh L, Lester W, Perry D, Madan B, Laffan M, et al. AAV5-factor VIII gene transfer in severe hemophilia A. N Engl J Med. 2017;377(26):2519-30. https://doi.org/10.1056/ NEJMoa1708483. 